\title{
Literatura na escola: uma proposta humanística
}

Odiombar Rodrigues ${ }^{1}$

Resumo: A discussão da relação literatura e educação evidencia dois posicionamentos sobre o assunto. Professores de literatura consideram-na valioso instrumento de formação crítica do aluno, enquanto pedagogos a veem como um repertório de texto. A literatura dispõe de preciosos instrumentos que contribuem para a formação do sujeito, reforçando suas identidade e atuação no contexto social. $\mathrm{O}$ apoio bibliográfico tem duas fontes principais: Jérôme Roger (2002) para os assuntos relacionados à crítica literária e Cecil Jeanine Albert Zinani (2006) serve como apoio para as relações de gênero e literatura. Este artigo propõe uma aplicação dos recursos teóricos com a finalidade de estabelecer uma metodologia adequada à fruição do texto como fonte de prazer e conhecimento. É uma contribuição aos professores de ensino fundamental e médio.

Palavras-chave: Leitura. Literatura. Docência.

\section{Introdução}

As relações entre Literatura e Educação têm recebido, dos estudiosos da área, muitas reflexões, e permitido debates interessantíssimos. O que propomos, neste texto, é a inclusão da Literatura como um instrumento importante para a consecução de objetivos educacionais que respeitem as diferenças de gênero e, ao mesmo tempo, promovam uma nova atitude diante das peculiaridades do aluno. Os estudos de gênero como uma categoria teórica oferece instrumentos valiosos para a atividade docente, principalmente como promoção do respeito às diferenças de gênero, classe e raça.

Vemos, a cada dia, uma redução do espaço da literatura nos currículos escolares. Este fenômeno se deve, em especial, ao enfoque dos professores no estudo deste componente curricular, em geral, sob uma visão teórico-histórica. A literatura torna-se um elemento isolado e desvinculado do contexto cultural do aluno. Por outro lado, as autoridades educacionais, centradas numa visão tecnicista da educação, priorizam os aspectos de racionalidade, eficiência e produtividade, deixando de lado a formação humanística do aluno, conforme alerta Dermeval Saviani: “... na pedagogia tecnicista o elemento principal passou a

\footnotetext{
${ }^{1}$ Mestre em Letras pela PUC-RS (1986) e Doutor em Letras pela UFRGS (1998). Professor aposentado da UFSM. Atualmente professor da Universidade Luterana do Brasil. Linhas de pesquisa: Estudos de Gênero; Literatura e Política; e Literatura e Representação. E-mail: prof.odiombar@gmail.com
} 
ser a organização racional dos meios, ocupando o professor e o aluno posição secundária" (SAVIANI, 2012).

A educação vive momentos de muitas carências, pois perdeu, há muito, a sua função primordial de "fonte do saber". O sistema educacional passou a concorrer com outros sistemas bem mais eficientes na transmissão do conhecimento e na sedução dos jovens. A pedagogia, na ânsia por "métodos e técnicas", esqueceu os conteúdos e esvaziou a sala de aula. Para os pedagogos, em geral, os aspectos metodológicos são prioritários em relação aos conteúdos abordados, deixando de lado os interesses do próprio aluno e suas subjetividades. A visão humanística da educação é advogada tanto por Paulo Freire (2003) que reconhece ser a educação um ato político, como por Karl R. Rogers (1997), que estabelece as três condições para a aprendizagem: autenticidade, empatia e aceitação incondicional.

O saber que a escola transmite, na maioria das vezes, está inadequado no tempo e no espaço, isto porque ela não percebe que a ciência, o saber e o conhecimento não são valores absolutos e isolados, mas interligados e interdependentes. A prática escolar tem oscilado entre uma visão sociológica que privilegia os problemas de grupos na determinação da prática educativa e uma perspectiva cognitivista que, alheia ao aluno, transmite conteúdos sem maior reflexão. De qualquer forma a educação realiza-se de um modo distanciado da visão humanística do aluno, enquanto sujeito de seu processo de aprendizagem. O abuso das "políticas inclusivas" que se centram em grupos sociais, acaba ignorando o "sujeito" como promotor de seu próprio conhecimento. O acolhimento do social não pode "apagar" as exigências do indivíduo.

A literatura, como repertório de vivências, permite à educação intervir de forma direta na formação crítica de cada aluno e fortalecer a interação e a integração ao grupo social. A literatura, enquanto fruição de texto é o elo entre indivíduo e sociedade. Os pedagogos têm ignorado este valioso aliado na consecução dos objetivos educacionais.

\section{Educação e Literatura}

Antes de qualquer coisa, o que se busca na relação educação e literatura não é uma visão esteticista da literatura, mas sim uma perspectiva que faz dela um instrumento de reflexão e aproximação do aluno com a sua realidade, ou seja, faz da literatura um instrumento de revelação da própria subjetividade. A leitura é apropriada para a construção do aluno como cidadão e como sujeito crítico. Brayner conceitua a leitura como: 
A leitura surge, assim, como o trabalho de autoconstrução subjetiva não determinada pelas "coisas ditas", um "eu" que se forja na forma de uma viagem interior e exterior "como uma experiência estética" (BRAYNER, 2005, p. 70).

Para determinar as relações entre educação e literatura é importante que se estabeleça, por princípio, que tal esforço não pode resultar numa prática literária subordinada à transmissão de ensinamentos, nem, tampouco, numa forma de "literaturização da pedagogia" (BRAYNER, 2005, p. 66). Neste contexto de relações, é importante que se defina a base teórica de atuação. A literatura, neste sentido, desfruta de um amplo espectro crítico-teórico para socorrer o professor em sua prática docente. Quando se fala em literatura, a referência não é a teoria ou a história literária, o que não faz sentido, principalmente, no ensino fundamental. Aqui a referência é a leitura enquanto instrumento de compreensão do mundo.

Essa parece ser uma dificuldade enfrentada por muitos professores de língua e literatura. Para eles é difícil conceber a leitura do texto de ficção, desconectado do aparato teórico e das informações biográficas. Cabe ao professor, como conhecedor destes aspectos, a tarefa de ordenar leituras que estabeleçam conexões com o mundo do aluno e com as suas vivências. Reconhecemos que Vidas Secas é um texto importante, muito além de sua linguagem ou sua conexão com o "romance de 30" é uma obra que cativa o leitor pelo conteúdo. Talvez, para o aluno, a morte da cachorrinha Baleia seja um foco capaz de conectá-lo com o mundo e com o próprio texto de forma mais intensa do que um discurso sobre ecologia ou uma discussão sobre as características do ciclo do romance da seca. O aluno se aproxima do texto pelo conteúdo e não pelos elementos formais, em outras palavras: "É por via da personagem que aderimos afetiva e intelectualmente à narrativa" (CADEMARTORI, 2009, p. 27). Com esta perspectiva, a literatura tem utilidade pedagógica independente do grau de ensino (fundamental ou médio).

Quando a escola transforma a literatura em conteúdo teórico, ela afasta o aluno da fruição do texto e da experiência da leitura como instrumento de autoconhecimento e de conhecimento do mundo. A leitura não é um elemento que se enquadra num programa de disciplina ou numa ação pedagógica, controlada por objetivos e instrumentos de avaliação formais. A leitura deve corresponder à vivência da escola. Muito mais eficiente seria a adoção de projetos de leitura no contexto escolar do que atividades isoladas por iniciativa de professores. Cabe à escola reconhecer o valor da leitura e incluí-la em seus "objetivos" permanentes. 
Para a consecução dos objetivos da literatura no âmbito escolar é necessária uma nova postura das autoridades educacionais, pois é a organização escolar que deve estar comprometida com a leitura, muito mais do que o professor de forma isolada. A escola, enquanto ensino (sala de aula), educação (práticas desenvolvidas) e espaço físico deve estar a serviço do desenvolvimento de projetos de valorização da leitura. No espaço físico da escola, muito mais do que a sala de aula, a biblioteca deve ser o promotor do hábito da leitura. Infelizmente, o que vemos em nossas escolas são bibliotecas que funcionam mais como um "depósito de livros" do que como um agente educador.

A grande função da leitura é formar leitores críticos e não elementos passivos, receptores de conhecimentos e sujeitos a avaliações objetivas. Não podemos conceber o desenvolvimento da leitura, no contexto escolar, como algo que se enquadra nos padrões pedagógicos pré-estabelecidos. A leitura leva o sujeito à capacitação crítica, principalmente do mundo que o cerca.

Esta discussão sobre o papel da escola parece ser a dificuldade maior, em especial pelo fato de que, no geral, as funções administrativo-pedagógicas são exercidas por pedagogos que estão mais voltados para os aspectos didáticos, relegando, para segundo plano, os conteúdos e a formação humanística do educando. No ambiente escolar, cabe aos professores de língua e literatura levantar a voz e impor projetos mais amplos do que a sala de aula. Cientes da polêmica levantada, retornemos à discussão do tema no âmbito da própria literatura.

Poderíamos examinar um conjunto de tendências da crítica que possibilitam uma abordagem do texto com uma finalidade mais adequada à prática pedagógica. Podemos apontar: a estética da recepção; a fenomenologia; a sociologia da literatura entre outras. Cada direcionamento destes é capaz de oferecer recursos importantes e diferenciados em sua eficácia, o que os tornam complementares e não excludentes. A estratégia de abordagem do texto compreende esta etapa teórica, mas isto é função do professor; ao aluno cabe receber um roteiro de leituras atraentes e motivadoras.

A estética da recepção permite uma abordagem que traz o próprio leitor para o centro das discussões, dando ênfase ao seu modo de perceber/ler o mundo e a sua própria construção. As expectativas do leitor são fator componente da formação do "sentido" da obra, pois a articulação entre texto e leitor é que evidencia as experiências e as contrapõem ao repertório oferecido pelo texto. O texto estabelece algumas estratégias para a sua leitura, ou seja, de forma implícita ou explícita ele oferece ao leitor um "roteiro" de sua leitura. Cabe ao professor evidenciar estes "portais do texto" que podem seduzir o leitor e levá-lo para um novo modo de percepção do texto que até então lhe era desconhecido. No momento em que o 
aluno se deixa "seduzir" pelo texto, ele se revela e desvenda o mundo que o cerca. Instrumentalizar a prática pedagógica com elementos da estética da recepção permite ao professor explorar com mais propriedade os mecanismos subjetivos da relação aluno-texto.

A fenomenologia contribui com a percepção do sujeito e seu horizonte de conhecimento. No surgimento da fenomenologia como instrumento de crítica literária, a quebra da tradição do estudo literário subordinado às "escolas literárias", foi o primeiro impacto que esta corrente crítica pode agregar aos estudos do texto. O desenvolvimento da percepção pode ser apontado como um dos principais objetivos desta corrente crítica.

Por fim, podemos apontar a sociologia da literatura ${ }^{2}$ como um instrumento apropriado para a discussão das relações sociais e da denúncia das opressões a que as classes menos favorecidas estão submetidas. Este conjunto teórico revela uma instrumentalização que permite a valorização do leitor, o desenvolvimento de sua percepção e a consciência social. Os estudos de gênero aproximam-se da sociocrítica e permitem trazer para a discussão temas contemporâneos como respeito às diferenças.

Nas relações que se estabelecem entre sociologia e literatura, duas posturas podem ser adotadas:

a) Uma enfoca o texto como produção social, portanto elemento representativo de grupos sociais e examina a "relação imaginária dos indivíduos com suas condições reais de existência" (ALTHUSSER, 1980, p. 101). Importante também é considerar a relação que se estabelece entre a estrutura do texto e a estrutura mental dos grupos sociais (GOLDMANN, 1976). Instrumentalizada desta forma, a literatura oferece um vasto campo para o exame dos processos de conscientização do sujeito.

b) A outra postura é centrada nas relações que o texto estabelece com o leitor, o que a aproxima da série literária e da visão fenomenológica do texto. Dando continuidade a estas especulações, pode-se alcançar a estética da recepção que, como aponta Jauss, é importante a percepção do sentido como interação constante entre efeito e recepção (JAUSS, 1994).

A sociocrítica, na verdade, não se constitui numa "escola" sistematizada, mas, pelo contrário, traz dentro de si uma variedade de tendências. O que dá certa unidade a ela é o fato de ter introduzido "a dimensão política no centro do fenômeno literário (...)" (ROGER, 2002,

\footnotetext{
${ }^{2}$ Alguns teóricos optam pelo termo sociocrítica, talvez fazendo paralelismo com psicocrítica.
} 
p. 115). A leitura, centrada em posturas teóricas como estas, pode estabelecer vínculos com práticas de linguagem vinculadas tanto à Linguística de Texto, quanto à Análise do Discurso ${ }^{3}$.

Este não é um único esquema, nem tampouco uma receita infalível. Cabe a cada mestre, diante de sua classe, determinar os instrumentos adequados para a sua intervenção em sala de aula. A multiplicidade da leitura não comporta práticas centradas em teorias fechadas, mas impulsiona o leitor à variedade de posturas diante deste mundo tão amplo.

Como se pode ver, não é uma questão de simples escolha, é, na verdade, o resultado de uma postura crítica assumida pelo professor e transformada em uma prática pedagógica. Com certeza, não cabe ao professor uma discussão de métodos com os alunos, mas sim uma prática bem fundamentada que resultará num eficiente processo de autoconhecimento do educando.

\section{A leitura e suas relações}

A leitura implica, também, um conjunto de relações que o professor não pode deixar de lado no momento de estabelecer seu plano de estratégias. Cada turma, cada grupo de alunos, tem peculiaridades que não podem ser ignoradas. $\mathrm{O}$ efeito de motivação, crítica e adesão ao texto depende das opções feitas pelo professor. O aluno aguarda por um texto que traga respostas às suas inquietações e, só assim, ele responderá com o engajamento à leitura.

A literatura, como instrumento pedagógico, exige atenção a muitos fatores como às diferenças de gênero, às relações de poder e aos instrumentos didáticos. Embora sejam questões externas à literatura, são elementos determinantes para o sucesso da leitura. O texto que o professor leva para a sala de aula é portador de possibilidades de reforço ou de destruição dos vínculos do aluno com a literatura.

A concepção de gênero como construção social é um liame que permite unir a literatura à educação e, ao mesmo tempo, partir para uma intervenção na prática educativa. No contexto de questões de gênero, fica fácil estabelecer uma aproximação com os direcionamentos sociológicos da crítica literária e dar resposta eficiente para as inquietações de cada aluno de acordo com suas vivências.

Em sala de aula, meninos e meninas têm reivindicações distintas, suas expectativas em relação ao saber não são coincidentes, porém a escola traz a eles os “conteúdos" ditados pelos interesses pedagógicos que, nem sempre, estão de acordo com a realidade do aluno, gerando

\footnotetext{
${ }^{3} \mathrm{AD}$ e leitura é tema do texto "Da interpretação à interdiscursividade", apresentado na VII Semana de Filologia da USP (maio de 2012, no prelo).
} 
conflito entre desejos individualizados e os parâmetros propostos pelo educador, especialmente em termos de avaliação.

Assim como o gênero, a classe e a raça são determinantes para o sucesso do texto em sala de aula. O professor não pode ficar alheio a estas variáveis e, muito menos, deixar de dar respostas adequadas a cada elemento destes grupos. Favorecer a inclusão social e incentivar o espírito crítico é muito mais do que distribuir "benesses" e privilégios é, acima de tudo, respeitar as diferenças sem deixar de promover o conhecimento.

$\mathrm{Na}$ escola, o exercício crítico da leitura, muitas vezes, fica dificultado pela organização social, pois o poder político, através de seus administradores, representado pelos pedagogos no ambiente escolar, exerce uma influência sobre professores, artistas e críticos no sentido de barrar a autonomia da arte em relação a sua função de formadora. Na sociedade, a mídia é a grande parceira deste descaminho da literatura, na medida em que transforma em espetáculo, o que é fruição pessoal do texto literário. O esforço combinado entre as instâncias do poder e da mídia tem como resultado a manutenção dos privilégios da classe dominante e a alienação, cada vez maior, dos destituídos de poder. O discurso pedagógico (alicerçado em ideologias alienantes), combinado com os meios de comunicação de massa (centrados no incentivo ao consumo) tem como resultado uma visão distorcida da literatura.

A questão do poder torna-se central nos estudos literários, pois dada a sua “invisibilidade" ele é capaz de determinar espaços e disciplinar o sujeito (FOUCAULLT, 1979). O professor, como leitor mais experiente, deixa de ser um incentivador dos alunos e reduz-se a reprodutor dos "métodos e técnicas" determinados pelos administradores da educação. A aprendizagem em literatura é uma tarefa bem mais complexa do que em outras disciplinas mais sujeitas aos fatos e à ciência. A docência em literatura não tem como resultado a aquisição de conhecimento, mas a construção do sujeito leitor.

Poder e saber são entidades que caminham paralelamente e se completam, "são aspectos imbricados, pois todo o poder institui um corpo de conhecimentos que, por sua vez, gera novas relações de poder (ZINANI, 2006, p. 59). Nas sociedades, os grupos que detêm o poder são responsáveis pelo gerenciamento do saber e, portanto, direcionadores do conhecimento ao encontro de seus interesses.

Não há a menor dúvida de que o professor deve instrumentalizar seu trabalho com recursos didáticos eficientes. Não é uma questão de arregimentar uma parafernália de “cartazes", "figurinhas" e "longas listas de objetivos", mas estabelecer estratégias de ação que estejam ao alcance do aluno e facilitem o acesso ao texto. A tecnologia disponibiliza diversos recursos que, quando bem empregados, são capazes de motivar, mas, quando mal 
empregados, são "eficientes" na tarefa de afastar o aluno do texto. Muitas vezes um professor usa o datashow porque é moda, mas o reduz a tarefa de suporte de leitura.

O trabalho com o texto em sala de aula, independentemente da postura teórica adotada, pode ser detalhado através de alguns procedimentos de leitura como observa Eni Orlandi ao propor três etapas (ORLANDI, 2007, p. 77):

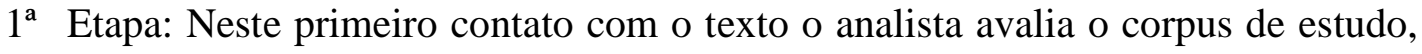
verificando os aspectos enunciativos e, assim, abrindo caminho para as probabilidades de percepção do discurso. É o momento de verificação das paráfrases, da verificação do dito e dos "silêncios" do texto e do estudo do vocabulário, verificando a seleção, significação, áreas semânticas e outros aspectos pertinentes. Esta primeira etapa é antecedida pela contextualização do objeto analisado, consolidando informações que podem ser necessárias para as relações entre a formação discursiva e a formação ideológica.

$2^{\text {a }}$ Etapa: Este é o momento em que o analista estabelece os fundamentos da formação discursiva e estende suas conclusões para a formação ideológica. A metáfora é o processo de "substituição" que revela os sentidos eleitos pelo locutor no texto. Este é o momento de análise da cadeia significativa, revelando as razões de dizer e não dizer, bem como "preencher" os "intervalos" presentes na textualidade. Este processo metafórico (deslizamento de sentido) é responsável pelas relações interdiscursivas que podem ser estabelecidas. A análise torna-se completa pelo exame da interpretação, da ideologia e da historicidade. Ao final desta etapa, o texto está aberto para a compreensão de sua plurissignificação.

$3^{\text {a }}$ Etapa: A terceira e última etapa é o momento de articulação do processo discursivo com a formação ideológica. Alicerçado nas análises internas da segunda etapa, o analista pode avançar para o estabelecimento das relações ideológicas que o texto comporta. Nesta etapa, o que domina é o aparato teórico arregimentado e a competência do próprio leitor.

Estas três etapas não podem ser imaginadas como procedimentos estanques, pelo contrário, no interior de uma já se manifestam as articulações das outras. Cada movimento de análise é como uma revelação da multiplicidade do texto e suas possibilidades de interpretação. 
Como se pode observar, este é um procedimento que não restringe o estudo do texto apenas ao campo da literatura, mas proporciona a salutar integração entre língua e literatura em sala de aula. Muitos professores ficam presos ao estudo da gramática por não perceberem que a literatura é uma porta de entrada para as discussões de linguagem.

O universo da literatura é muito mais amplo do que a teoria e a história literária, o texto estabelece relações dentro do estudo da linguagem e também com outros componentes curriculares como história, geografia, sociologia, filosofia e muitos outros. Neste momento se reforça a sugestão de que a literatura ultrapassa os limites da sala de aula e deve abranger a escola como um todo através de projetos bem elaborados. Não reconhecer esta vocação da literatura é restringi-la a mero componente curricular, perdendo o potencial que ela tem para estabelecer relações que permitam a formação integral do aluno.

\section{O professor e o texto}

A intervenção do texto literário, como elemento que permite escolhas, preenche este espaço entre o desejo da criança e os conteúdos pré-determinados. O texto literário não é o objeto de aprendizagem, mas funciona como instrumento de autoconhecimento e desenvolvimento emocional, condições indispensáveis para a aprendizagem. A relação que se estabelece entre professor - texto - e aluno é o instrumento eficaz para a promoção da aprendizagem e do autoconhecimento.

Cabe ao professor intervir como mediador, na medida em que recupera a literatura como fonte de prazer e conhecimento. Por outro lado, a sala de aula tem sofrido a pressão dos "programas" que transformam a prática da leitura em uma sequência de informações, muitas vezes, desconectadas e supérfluas. Programas pré-estabelecidos e/ou direcionados a eventos, como vestibular, são nefastos à fruição prazerosa do texto literário.

A leitura é um campo de experimentação, no qual o aluno pratica o conhecimento e o professor providencia os instrumentos (textos) adequados às necessidades de crescimento do estudante. A ciência não progride só com acertos, mas o seu progresso deixa para trás um rastro de erros e incompreensões. Muitas vezes a certeza tem que ser desconstruída para que o conhecimento possa avançar, ou seja, cada seleção de texto é uma experimentação que pode levar ao sucesso ou à renovação do trabalho. Cada aula de literatura é uma dúvida e, ao mesmo tempo, uma esperança de sucesso.

O que sempre deve estar presente para o professor, no momento de sua prática docente, é o fato de que a grande maioria dos alunos não terá como função futura a docência em 
literatura. São sujeitos que irão exercer profissões muito diversas, mas que, para todos, a literatura poderá continuar como um marco referencial na aquisição de conhecimento e lazer.

No cotidiano da sala de aula, duas direções se impõem ao professor: desenvolver um conteúdo que contemple as provas de vestibular e concorrer com os "cursinhos", ou formar indivíduos comprometidos com o conhecimento e aptos a prosseguirem seus estudos. Se enveredar pelo primeiro caminho, tem o respeito dos alunos e a aprovação dos pais; se trilhar o segundo, sentir-se-á isolado e deverá enfrentar uma forte resistência dos alunos que buscam, em primeiro lugar, uma série de informações para resolver as questões de vestibular.

No meio deste jogo duro é que o professor de literatura exerce a sua missão. Importante observar que os professores de outras disciplinas, principalmente as exatas, não vivenciam tal dicotomia, pois os seus conteúdos programáticos aproximam-se muito mais da informação do que da formação.

É fundamental repensar este ensino, adequando-o à realidade vivenciada. É necessário que se desenvolva uma metodologia que contemple o conhecimento exigido nas provas de vestibular, mas, ao mesmo tempo, proporcione um crescimento do aluno enquanto sujeito e ser crítico, engajado na sociedade. Não se defende uma metodologia que contemple uma postura hedonística, mas uma atitude que capacite o aluno para enfrentar os concursos e o promova como ser humano e como sujeito pensante, afastando-o da posição de intelectuais “orgânico-conservadores”, como classifica Gramsci.

O desafio é encontrar um meio termo entre estes dois caminhos e, concomitantemente, produzir um conhecimento que faça uso das tecnologias disponíveis, colocando-as a serviço do conhecimento literário. Criar, na sala de aula, um ambiente crítico e transformador, parece ser o primeiro passo. Com este propósito foi desenvolvido o presente projeto que nada mais é do que uma metodologia que transforma a literatura em um instrumento de formação de cidadania.

O professor, como intelectual e formador de opinião, não pode refugiar-se em conteúdos meramente teóricos para apresentar aos seus alunos. Assim procedendo, ele deixa de receber a admiração de seus pupilos e, com certeza, desfaz os vínculos entre eles e a disciplina. Antes de qualquer coisa, o professor é o exemplo de leitor que o aluno tem mais próximo de sua observação.

Impossível não recorrer às palavras de Abramovich para elucidar esta relação afetiva entre professor-texto-aluno: 
Leitura é paixão, é entrega, tem que ser feita com tesão, com ímpeto, com garra de quem lê e de quem indica. Com trocas saboreadas e não com perguntas fechadas e sem espaço pra opinião própria, pensada, sentida, vivida. Senão, é só pura obrigação. E aí, como tudo o mais na vida, não vale a pena. Mesmo (ABRAMOVICH, 1999, p. 56).

\section{A sociedade contemporânea e a literatura}

A perspectiva tecnológica, mecanicista e pragmática da sociedade contemporânea caminha em direção a "unidimensionalidade" do homem (MARCUSE, 1979). Esta escola "cientificizada" considera o aluno como um ser abstrato, sem flexioná-lo em suas diversas

dimensões como sexo, classe e raça. O professor, consciente de sua tarefa, é capaz de reordenar o conhecimento e dar ao aluno uma visão de conjunto que o texto literário pode oferecer.

As diferenças entre os alunos são fatores que evidenciam por si só a fragilidade do conhecimento como algo absoluto, pois o aprender está mediado pela própria capacidade de percepção do sujeito. A leitura é um objeto que só se revela na medida em que o olhar de cada um é capaz de construir a sua compreensão. O ato de ler é um ato de construção do conhecimento e na mesma proporção da construção da subjetividade do leitor. Este caráter múltiplo da leitura é que a habilita a tornar-se elemento central do processo educativo.

O mundo globalizado exige cada vez mais a visão plural do conhecimento, pois os saberes estão interligados e estabelecem uma rede que a escola ignora ao fragmentar o conhecimento numa multiplicidade de "disciplinas". A visão de conjunto deve prevalecer sobre a especialização, pois assim o cidadão forma-se no pleno exercício de sua cidadania, pelo acesso livre e universal ao conhecimento e aos bens sociais.

O aluno não aprende uma questão de física ou um fato histórico de forma isolada, mas no contexto que interliga todos os saberes. Mais uma vez, percebe-se a função importante que a literatura exerce, pois o texto literário é um microcosmo que se abre para o aluno exercitar as suas capacidades de percepção e conhecimento. A literatura como representação é o ensaio permanente que o aluno executa como indivíduo e como ser social.

A relação entre literatura e contemporaneidade passa pelo impacto que os meios eletrônicos exercem sobre o livro, bem como pelas diversas solicitações do mercado consumista a que o aluno está submetido. As discussões sobre as relações entre os modos tradicionais de leitura e os oferecidos pela mídia vamos deixar para outro momento. Faremos algumas reflexões sobre a literatura diante da sociedade atual. 
Não há dúvida de que as mídias trazem novas formas de recepção do texto, mas, deixando de lado o meio, podemos dizer que o texto literário tem tido uma divulgação bem maior. A internet e a televisão contribuem decisivamente para o acesso do aluno ao texto e ao autor. O aluno lê com informações que são muito mais eficientes do que longas biografias, pois tem acesso a entrevistas de escritores que, em outros tempos, seria impossível. As informações sobre o livro e o autor são de outra ordem e muito mais motivadoras.

A literatura está muito mais diversificada, pois os gêneros textuais se multiplicaram e possibilitaram uma grande gama de opções para os leitores. Hoje encontramos adolescentes lendo textos extensos que jamais imaginaríamos encontrar anos atrás. Escritores e editoras têm desenvolvido esforços no sentido de captar o gosto do leitor e oferecer produtos para mercados diferenciados. Hoje, um mesmo texto pode ser oferecido em suportes como livro, filme, CD, DVD, HQ ou $e$-book.

A circulação das obras está menos influenciada pela crítica literária e pelos educadores e bem mais determinada pelos meios de comunicação e pela influência direta de leitores. Os adolescentes leem J. K. Rowling (Harry Potter) porque o amigo indicou ou o cinema incentivou e não porque a crítica indicou.

$\mathrm{O}$ aspecto formal que se estabelecia entre autor-obra-leitor, hoje perde sentido, pois qualquer um, com acesso à internet, pode lançar-se como escritor e tornar-se conhecido com apenas alguns toques. Não faz sentido recusar estes novos gêneros, pois eles já estão sólidos entre os novos leitores. Estes caminhos da literatura abrem espaço para muitos leitores que, pelos meios tradicionais, não teriam acesso à obra literária.

\section{Conclusão}

A interdisciplinariedade, vista aqui como o cruzamento entre Educação, Literatura e Crítica, é o caminho que se abre para que a educação se torne um foco de interesse do aluno, pois a multiplicidade de visões sobre cada bloco de conhecimento leva, com certeza, a uma postura de pluralidade e tolerância. A escola que se fecha numa visão objetiva, centrada em programas e planos fixos, esquece a multiplicidade de solicitações a que o aluno está submetido na sociedade contemporânea.

A formação do professor de literatura é uma tarefa complexa, pois o acadêmico, quando entra no Curso de Letras, não tem a noção clara de que ensinar literatura é antes de tudo ler. Não há professor de literatura dissociado do prazer de ler. Neste sentido, entende-se que o professor de literatura tem como pré-requisito o gosto pela leitura. $\mathrm{O}$ curso acadêmico pode 
trazer-lhe muita informação, mas isto não é suficiente para torná-lo um profissional profundamente comprometido com a formação de novos leitores. De nada, ou pouco adianta o treinamento com métodos e técnicas pedagógicas modernos, o que vale mesmo é o conhecimento literário e a prática da leitura. $\mathrm{O}$ aluno aprende a ler com um professor-leitor.

Um novo mundo se abre para a literatura e o professor não pode restringir-se aos métodos tradicionais para levar aos alunos o grande acervo cultural contido nas obras literárias. Todos os recursos da mídia devem ser explorados, com competência, pelo professor a fim de que encurte a distância entre a sala de aula e o mundo tecnológico que se abre diante dos alunos.

Encerrando este artigo, deixamos aos leitores e desafio de buscar um modelo de prática de leitura que privilegie a formação crítica do aluno e rompa com os esquemas tradicionais e ultrapassados da educação formal que é oferecida às nossas crianças.

\section{Referências bibliográficas:}

ABRAMOVICH, Fanny. In: PRADO, Jason; CONDINI, Paulo (Orgs.) A formação do leitor: pontos de vista. Rio de Janeiro: Argus, 1999.

ALTHUSSER, L. Posições 2. Rio de Janeiro:Graal, 1980.

BRAYNER, Flávio Henrique Albert. Como salvar a educação (e o sujeito) pela literatura: sobre Philippe Meirieu e Jorge Larrosa. Revista Brasileira de Educação, mai.-jun./jul.-ago. 2005, n. 29, p. 63-72.

CADEMARTORI, Lígia. O professor e a literatura. Belo Horizonte: Autêntica. 2009

FOUCAULT, Michel. Microfísica do poder. Rio de Janeiro: Graal, 1979.

FREIRE, Paulo. Pedagogia da Autonomia: saberes necessários à prática educativa. 26. ed. São Paulo: Paz e Terra, 2003. Disponível ainda em: http://www.webartigos.com/artigos/.

GOLDMANN, Lucien. Sociologia do romance. 3. ed. Rio de Janeiro: Paz e Terra, 1976.

GRAMSCI, Antonio. Os intelectuais e a organização da cultura. 9. ed. Rio de Janeiro: Civilização Brasileira, 1995.

JAUSS, Hans Rovert. A história da literatura como provocação à teoria literária. São Paulo: Ática. 1994.

MARCUSE, Herbert. A ideologia da sociedade industrial. 5. ed. Rio de Janeiro: Zahar, 1979.

ORLANDI, Eni Puccinelli. As formas do silêncio: no movimento dos sentidos. Campinas, SP: Editora Unicamp, 2007. 
ROGERS. Karl R. Tornar-se Pessoa. 5. ed. São Paulo: Martins Fontes, 1997.

ROGER, Jérôme. A crítica literária. Rio de Janeiro: Difel, 2002.

SAVIANI, Demerval. Pedagogia tecnicista. www.histedbr.fae.unicamp.br/navegando/p.html. Acesso em junho de 2012.

ZINANI, Cecil Jeanine Albert. Leitura e gênero: a construção da identidade feminina. Caxias do Sul, RS: EDUCS, 2006.

Literature in the schools: a humanistic proposal

\begin{abstract}
The discussion of the relationship between education and literature reveals two positions on the subject. Literature teachers consider it a valuable tool for their student's critical thought, while pedagogues see it as a repertoire of text. Literature has valuable instruments that contribute to a person's formation, reinforcing their identity and ability to act on their social context. The bibliographic support has two main sources: Jérôme Roger (Roger: 2002) for issues related to literary criticism and Jeanine Albert Cecil Zinani (ZINANI: 2006) serves as support for gender relations and literature. We propose an application of the theoretical resources in order to establish a methodology suited to the fruition of the text as a source of pleasure and knowledge. This paper is a contribution to teachers from Elementary to High School.
\end{abstract}

Key words: Reading. Literature. Teaching. 